\title{
SALINITY TOLERANCE OF GRAFTED WATERMELON SEEDLINGS
}

\author{
ViKTÓRIA BÖHM, * DÁvid FeKeTe, ${ }^{1}$ GÁBor BALÁzs, ${ }^{1}$ \\ LÁSZLÓ GÁSPÁR ${ }^{2}$ and NOÉMI KAPPEL ${ }^{1}$ \\ ${ }^{1}$ Szent István University, Faculty of Horticultural Science, Department of Vegetable and Mushroom \\ Growing, H-1118, 29-43 Villányi Street, Budapest, Hungary \\ ${ }^{2}$ Szent István University, Faculty of Horticultural Science, Department of Plant Physiology and Plant \\ Biochemistry, H-1118, 29-43 Villányi Street, Budapest, Hungary
}

(Received: July 21, 2017; accepted: September 10, 2017)

In order to evaluate the salinity tolerance of grafted watermelon, two sets of experiments were conducted in a growing chamber where 'Esmeralda' varieties were grafted onto interspecific squash (Cucurbita maxima Duch. $\times$ Cucurbita moschata Duch.) and Lagenaria siceraria rootstocks. Both non-grafted and self-garfted plants were used for control. For salt stress, 2.85 and $4.28 \mathrm{mM} / 1$ substrate doses of $\mathrm{NaCl}$ were added with each irrigation in 2 day intervals for a duration of 23 days. Interspecific-grafted plants showed the highest salinity tolerance as plant biomass and leaf area were not decreased but improved by salinity in most cases. Furthermore, transpiration and photosynthesis activity did not decrease as much as it did in the case of other grafting combinations. Interspecific and Lagenaria rootstocks showed sodium retention, as elevation of $\mathrm{Na}^{+}$content in the leaves of these grafting combinations was negligible compared to self-grafted and non-grafted ones. Presumably abiotic stress tolerance can be enhanced by grafting per se considering measured parameters of self-grafted plants did not decrease as much as seen in non-grafted ones.

Keywords: Grafted watermelon - interspecific rootstock - Lagenaria - salinity stress

\section{INTRODUCTION}

Grafting vegetables onto compatible rootstocks offers a number of advantages; for instance helps to compete biotic and abiotic stress [27, 11]. Grafting has been used to induce resistance against low [4] and high [27] temperatures and against iron chlorosis in calcareous soils [27], to enhance nutrient uptake and mineral nutrition [24, 31], to increase synthesis of endogenous hormones [23], to reduce uptake of persistent organic pollutants from agricultural soils [22], to raise salt and flooding tolerance [14, $35]$, and to limit negative effects of boron and copper toxicity $[13,30]$.

Salinity is one of the major abiotic stresses that could reduce plant growth. In many irrigated areas of arid and semi-arid regions, farmers are forced to use saline water to irrigate their crops due to an inadequate supply of fresh water [8]. Salinity can cause complex and several physiological, morphological and metabolic changes in plants through physical and chemical stresses [5,3]. Deleterious effects of salinity on plant

\footnotetext{
*Corresponding author; e-mail address: viktoriabohm@gmail.com
} 
growth are associated with low water potential of the root medium. This leads to a water deficit in the plant and toxic effects of ions mainly $\mathrm{Na}^{+}, \mathrm{Cl}^{-}$, and $\mathrm{SO}_{4}{ }^{2-}$ and nutritional imbalance caused by reduced nutrient (e.g., $\mathrm{K}^{+}, \mathrm{Ca}^{2+}, \mathrm{Mg}^{2+}$ ) uptake and/or transport to the shoot $[1,19,32,16,35]$.

Grafted plants develop numerous physiological and biochemical mechanisms to cope with salt stress, such as salt exclusion in the shoot and retention of salt ions in the root, better maintenance of potassium homeostasis, compartmentation of salt ions in the vacuole, accumulation of compatible solutes and osmolytes in the cytosol, activation of an antioxidative defense system, and induction of hormones mediated changes in plant growth [9]. Rootstocks can decrease the accumulation of $\mathrm{Cl}^{-}$and $\mathrm{Na}^{+}$ in Cucumis melo scion leaves [29]. Apart from $\mathrm{Na}^{+}$levels in the shoot, another component of plant salinity tolerance is the capability of the tissue to tolerate $\mathrm{Na}^{+}$[20]

Recently, grafting onto a salt-tolerant rootstock has been shown to be an efficient and environmental friendly technique for eliminating or reducing loss in production caused by salinity in high-yielding genotypes belonging to the Solanaceae and Cucurbitaceae families [9].

The aim of this study was to compare salinity tolerance of two commonly used rootstock for watermelon (interspecific squash hybrid and Lagenaria). In grafting experiments both non-grafted and self-grafted plants are rarely used simultaneously for control. In this study the effect of grafting itself on salinity tolerance was also monitored as both non-grafted and self-grafted watermelon were used for control.

\section{MATERIAL AND METHODS}

\section{Experimental design}

Two experiments (autumn 2012 and spring 2014) were conducted in Conviron growing chamber at the Corvinus University of Budapest, Faculty of Horticultural Science, Department of Plant Physiology and Plant Biochemistry to evaluate salinity tolerance of grafted watermelon (Citrullus lanatus (Thunb.) Matsum \& Nakai 'Esmeralda' F1). Two commonly used rootstocks for watermelon were chosen: Lagenaria siceraria 'DG-01' F1 (L) and Cucurbita maxima $\times$ Cucurbita moschata 'Shintosa F-90' F1 interspecific squash hibrid (INT). The effect of grafting itself on salinity tolerance was also studied, since both non-grafted (NG) and self-grafted (SG) watermelons were used for control. Non-grafted watermelon and rootstocks seeds were sown directly into plastic filled with $600 \mathrm{ml}$ perlite. Seedlings were grafted by hand, applying the one-cotyledon grafting method. After 1 week spent in grafting chamber, plants were grown in controlled environment $\left(100-250 / 0 \mu \mathrm{mol} \mathrm{m}^{-2} \mathrm{~s}^{-1} 16 \mathrm{~h} / 8 \mathrm{~h}, 2{ }^{\circ} \mathrm{C} /\right.$ $20{ }^{\circ} \mathrm{C}, 70 \% / 70 \%$ relative humidity). Seedlings were irrigated with Yara Ferticare (NPK 15:30:15+ microelements) and supplemented with Yara Liva Calcinit in 0.2 $\mathrm{m} / \mathrm{m} \%$ concentration. Before salinity treatment started, every pot had been placed into a nylon bag and tied by the base of the stem. The weight of the plants was measured before irrigation and after irrigation in 2 day intervals. The transpiration $(\mathrm{T})$ of 
the plants was calculated from the weight difference. Irrigation was planned, based on the average $\mathrm{T}$ of the control plant group from each grafting combination. The treatments were initialized 3 weeks after grafting and consisted of 3 treatments (control (0), 2.85 (I) and 4.28 (II) $\mathrm{mM} / 1$ substrate $\mathrm{NaCl} /$ irrigation). Every plant (each pot) was irrigated with the same amount of fertilizer solution and $\mathrm{NaCl}$ solution, diluted with deionized water based on the average $\mathrm{T}$ rate of the control plants. Treatments were applied in 2 day intervals for the duration of 23 days (The $\mathrm{NaCl}$ concentration reached 31 and $47 \mathrm{mM} / 1$ substrate at the end of the experiment). Treatments were arranged in a randomized complete-block design having 6 replicates per treatment.

\section{MEASUREMENTS}

On the 8th (in 2014) and 18th day (in 2012 and 2014) of the experiment photosynthetic activity (A) of the youngest fully expanded leaves of each plant were measured with LCi SD Portable Photosynthesis and transpiration rate analyzer. After the 2nd photosynthesis measurement, the same leaves were collected for water potential measurement. Water potential was measured with WP4 Water Potential Meter (Decagon Devices, USA). Transpiration (T) was calculated from the weight of the plants before and after irrigation, throughout the treatments. $\mathrm{T}$ was calculated to $\mathrm{g}$ water $/ 24$ hours. At the end of the experiment plants were harvested and their leaves were scanned and leaf area (LA) was calculated by Adobe photoshop software afterwards. Fresh weight (FW) and dry weight (DW) of the different parts of the plants were measured (shoot, leaf, stem, roots). In the case of experiment conducted in 2014, a developing leaf and a base leaf were collected from each plant during harvest, polyphenol content and antioxidant capacity (FRAP $=$ Ferric Reducing Ability of Plasma) were measured. Polyphenol content was determined by UV-vis spectrophotometric procedure with Folin Ciocalteu reagent at $\lambda=760 \mathrm{~nm}$ [32]. Antioxidant capacity was determined according to the method of Benzie and Strain [2] by spectrophotometry at $\lambda=593 \mathrm{~nm}$. $\mathrm{Na}^{+}$content of leaves and roots were determined from homogeneous sample of 6 plants by ICP-OES (IRIS Thermo Jarrel ASH, Corp., Franklin, MA, USA) spectrometer.

All data (except $\mathrm{Na}^{+}$content) obtained from the measurements were evaluated statistically by IBM SPSS (SPSS Inc. 2004) software. Multifactor ANOVA and Tukey post-hoc tests were used to compare data. In some cases when variances were unequal, Games-Howell tests were used instead of Tukey.

\section{RESULTS}

\section{Biomass and leaf area (LA)}

Decreasing tendency of biomass FW was observed by the severity of salinity stress in NG and SG plants, on the contrary in the case of L and INT plants stem FW and 
(a)

2012

口Stem घ Leaves

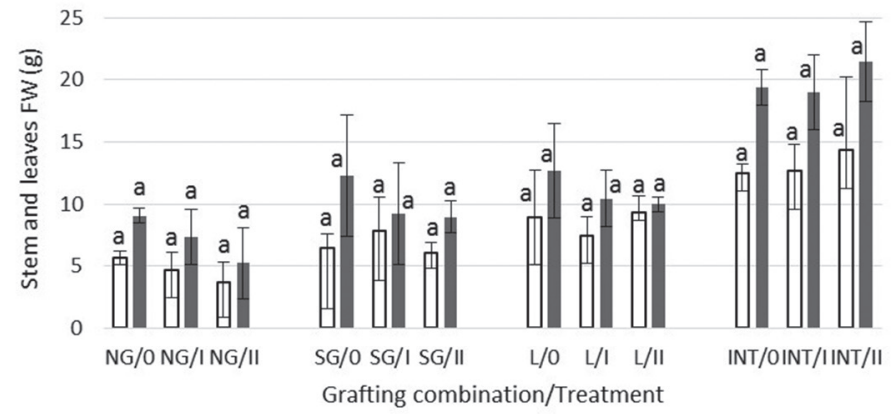

2014 口Stem घLeaves

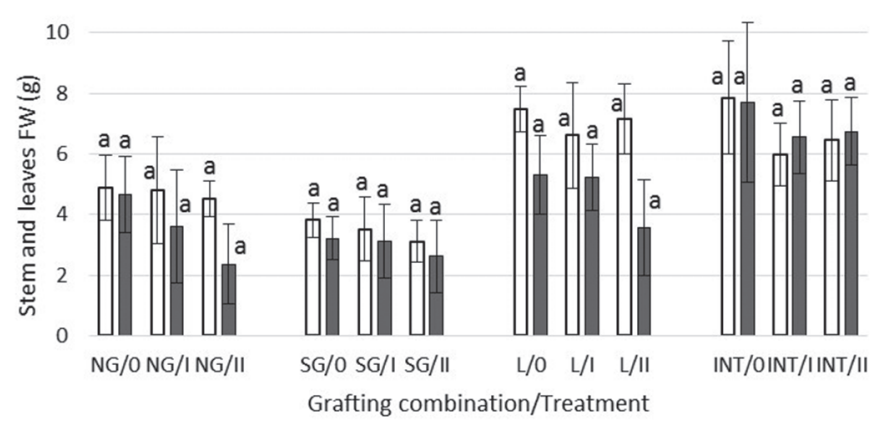

(b)

2012

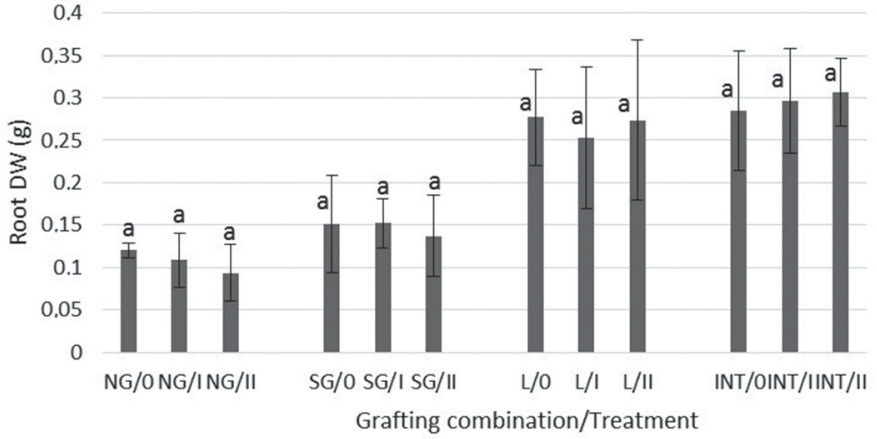

2014

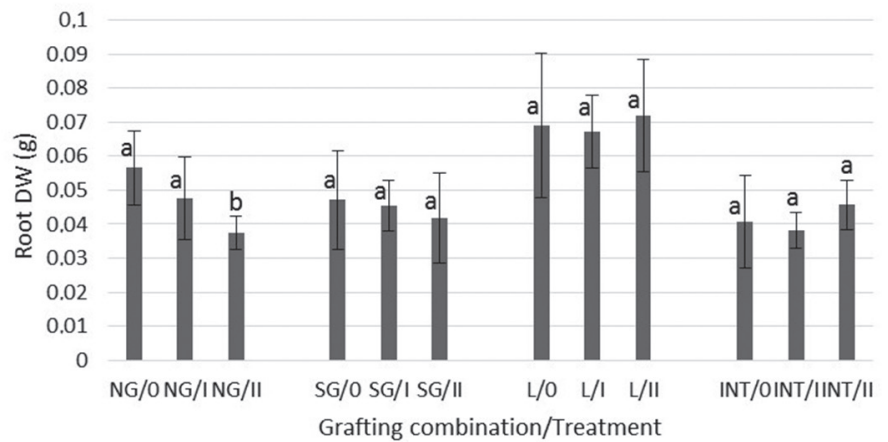



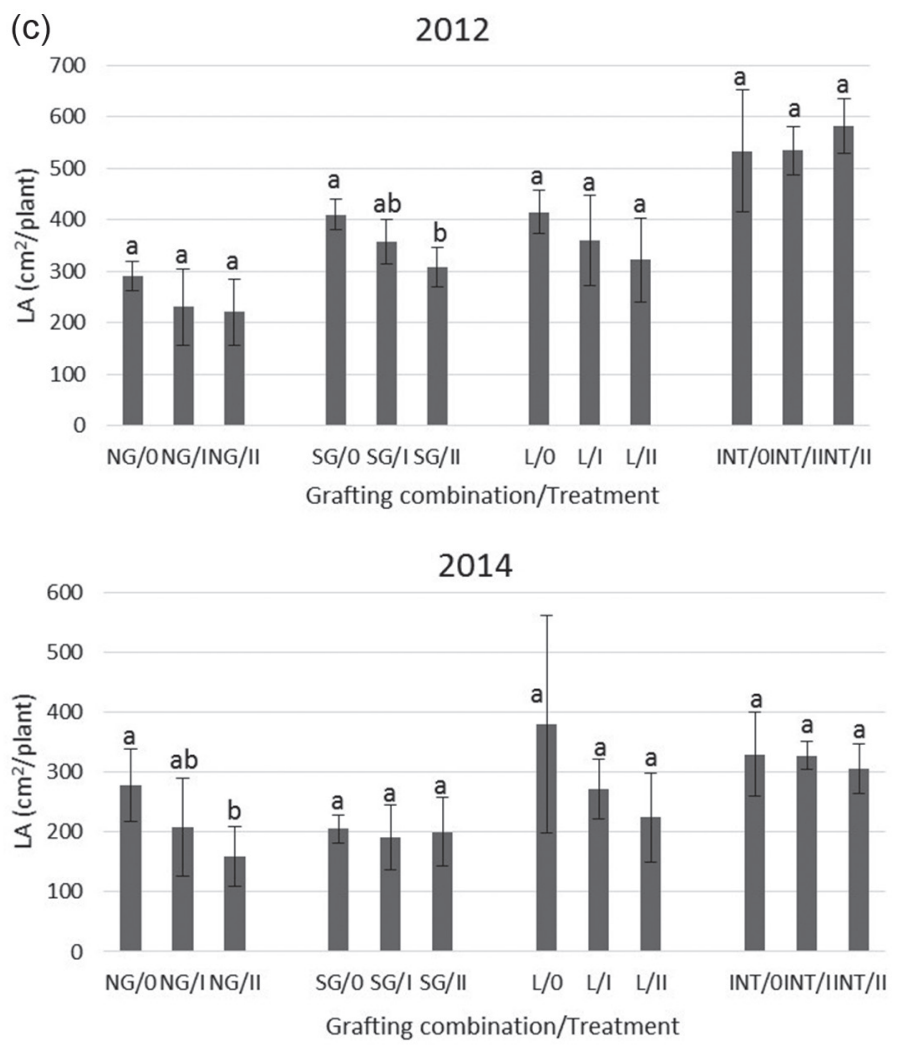

Fig. 1. The effect of salinity stress on stem and leaves fresh weight (FW) (a) root dry weight (DW) (b) and leaf area (LA) (c) Note: Bars indicate s.e. and different letters indicate significant differences at $P<0.05$. NG: non-grafted watermelon. SG: self-grafted watermelon. L: watermelon grafted onto Lagenaria siceraria. INT: watermelon grafted onto Cucurbita maxima $\times$ Cucurbita moschata. 0: control. I. II: salt treatments

leaves FW increased in salt treatment II compared to salt treatment I (Fig. 1). Roots DW of INT and L in experiment 2012 and roots of L in experiment 2014 were significantly bigger compared to NG and SG plants (Fig. 1).

Changes in LA are corresponding to the leaf FW and DW, affected significantly by the grafting combination $(P<0.001)$ and also by salinity stress $(P<0.05)$ (Table 1$)$, although only treatment II reduced the LA significantly (Fig. 1). Comparing the effect of salinity stress on the different grafting combinations, treatment II caused significant decrease in the LA of SG plants in 2012 and NG plants in 2014. 
Table 1

Results of the ANOVA on selected features of plant stress response in 2 experiments

\begin{tabular}{|c|c|c|c|c|c|c|}
\hline & & 2012 & & & 2014 & \\
\hline & $\begin{array}{c}\text { Graft } \\
\text { combination }\end{array}$ & $\begin{array}{l}\text { Salinity } \\
\text { treatment }\end{array}$ & $\begin{array}{l}\text { Graft } \times \\
\text { Salinity }\end{array}$ & $\begin{array}{c}\text { Graft } \\
\text { combination }\end{array}$ & Salt treatment & $\begin{array}{l}\text { Graft } x \\
\text { Salinity }\end{array}$ \\
\hline FW shoot (g) & $* * *$ & ns & $\mathrm{ns}$ & $* * *$ & $*$ & $*$ \\
\hline FW stem (g) & $* * *$ & ns & ns & $* * *$ & ns & ns \\
\hline FW leaf (g) & $* * *$ & $\mathrm{~ns}$ & ns & $* * *$ & $*$ & ns \\
\hline FW root $(\mathrm{g})$ & $* * *$ & ns & ns & $* * *$ & ns & ns \\
\hline DW shoot (g) & $* * *$ & ns & ns & $* * *$ & ns & ns \\
\hline DW stem (g) & $* * *$ & ns & ns & $* * *$ & $*$ & ns \\
\hline DW leaf (g) & $* * *$ & ns & ns & $* * *$ & ns & ns \\
\hline DW root $(\mathrm{g})$ & $* * *$ & ns & ns & $* * *$ & $*$ & ns \\
\hline $\begin{array}{l}\text { Water potential } \\
(\mathrm{Mpa})\end{array}$ & * & $* *$ & ns & ns & $* *$ & ns \\
\hline $\begin{array}{l}\mathrm{A}^{\mathrm{a}} \\
\left(\mu \mathrm{mol} \mathrm{CO}_{2} / \mathrm{m}^{2} / \mathrm{s}\right)\end{array}$ & - & - & - & ns & ns & ns \\
\hline $\begin{array}{l}\mathrm{A}^{\mathrm{b}} \\
\left(\mu \mathrm{mol} \mathrm{CO}_{2} / \mathrm{m}^{2} / \mathrm{s}\right)\end{array}$ & $\mathrm{ns}$ & $*$ & ns & ns & $* *$ & ns \\
\hline $\mathrm{LA}\left(\mathrm{cm}^{2} /\right.$ plant $)$ & $* * *$ & $*$ & $\mathrm{~ns}$ & $* * *$ & $*$ & ns \\
\hline Polyphenol (mg/l) & - & - & - & $* * *$ & $* * *$ & $* * *$ \\
\hline FRAP (mM/l) & - & - & - & $* * *$ & $* * *$ & $* * *$ \\
\hline
\end{tabular}

Note: ns - non-significant differences; *significant differences at $<0.05 ; * *$ significant differences at $P<0.01$; *** significant differences at $P<0.001$. ${ }^{a} 8$ th day of the initial salinity stress. ${ }^{b} 18$ th day of the initial salinity stress.

\section{Water potential and photosynthetic activity}

Leaf water potential significantly changed due to salinity. Although the analysis showed statistical difference only in case of L plants, the water potential of NG plants were strongly diminished by salinity. On the other hand it was only slightly reduced in case of INT (Fig. 2).

Photosynthetic activity of the plants did not decrease significantly on the 8th day after the first salt treatment (Table 1). However in NG plants there was a greater decrease compared to the other grafting combination. Salinity treatments significantly affected photosynthetic activity of the plants 18 days after the initialization of salinity treatment in both experiments (data of experiment 2014 is shown in Fig. 3). But the photosynthetic activity of the INT plants in the II treatment was still twice bigger than all the other grafting combinations. The photosynthetic activity of SG 
Grafting combination/Treatment

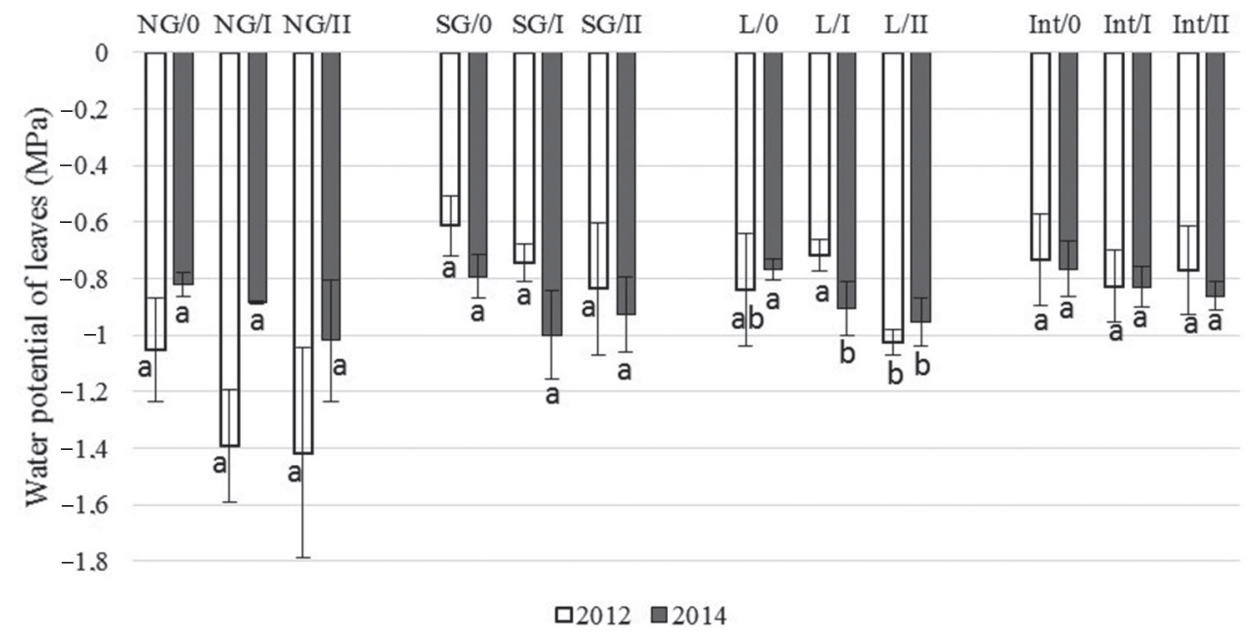

Fig. 2. The effect of salinity stress on leaf water potential. Note: Bars indicate s.e. and different letters indicate significant differences at $P<0.05$

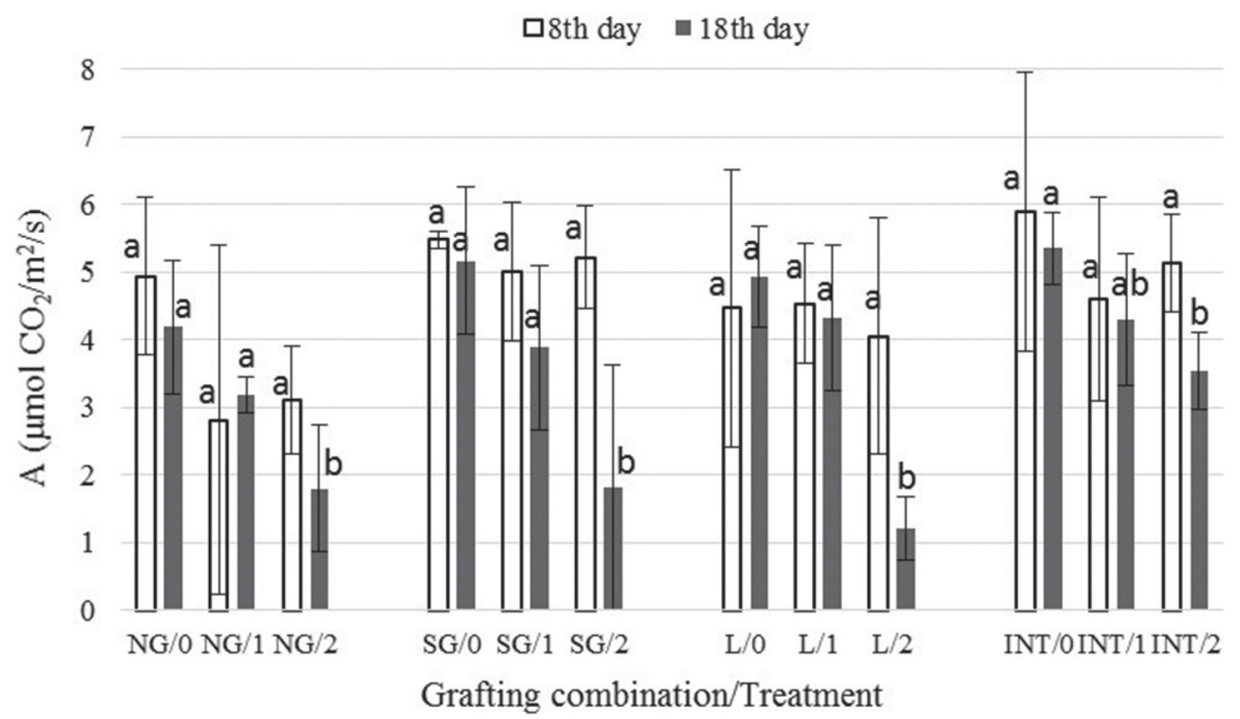

Fig. 3. Effect of salt treatment on photosynthesis activity in experiment 2014. 8 and 18 day after the initialization of the salinity treatments. Note: Bars indicate s.e. and different letters indicate significant differences at $P<0.05$ 
plants were higher in the control and treatments as well comparing to NG plants, the results reached and sometimes exceeded the photosynthetic activity of L and INT plants.

\section{Transpiration (T)}

Changes in $\mathrm{T}$ compared to control plants (average T/grafting combinations in \%) is presented in Fig. 4. Salt treatments reduced the T of plants but there were differences in the level of decrease by grafting combinations. T decrease of NG plants was the most obvious, declining to $71.2 \%$, and to $51.5 \%$ during the I salt treatment and to $38.9 \%$, and $45.6 \%$ in the II salt treatment by completion of the experiments. However $\mathrm{T}$ of $\mathrm{L}$ and INT did not decrease to such an extent (L: I treatment: $92.5 \%, 78.9 \%$ II treatment: $77.1 \%, 64.8 \%$, INT: I treatment: $88.1 \%, 76.8 \%$, II treatment: $74.5 \%$, $58.5 \%$ ). T of SG plants was higher (I treatment: $60 \%, 80.5 \%$, II treatment: $57 \%$, $73 \%$ ) than of NG ones (I treatment: $71.2 \%, 51.5 \%$, II treatment: $38.9 \%, 45.6 \%$ ) by the end of the experiment (except the I treatment in 2012). Moreover T of SG showed similarity to the L and INT in experiment 2014. From the graphs it can be observed that T of INT plants was stronger in the II treatment compared to I treatment for an extended period, observed in both experiments.

\section{FRAP and polyphenol content}

Concerning the FRAP of leaves, significant differences in salt treatments, grafting combination and leaf level were observed. FRAP was higher in developing leaves than in basal leaves (Fig. 5). The II salt treatment significantly increased FRAP in every grafting combination, except L. The most conspicuous increase can be seen in case of SG plants. In case of L and INT the II salt treatment did not result in increased FRAP compared to the I salt treatment.

Polyphenol content of developing leaves was significantly higher than that of the basal leaves (except in case of L). Polyphenol content was significantly higher in NG plants compared to other grafting combinations. The II salt treatment caused significant increase in all grafting combinations except INT (both leaf levels) and L basal leaves. Polyphenol content of the leaves of INT and L increased in I treatments compared to control, but II salt treatment did not cause further notable growth. Moreover in case of INT, developing leaves and L basal leaves polyphenol content decreased in II salt treatment compared to I salt treatment.

\section{$\mathrm{Na}^{+}$content of the plants}

The I salt treatment strongly increased the $\mathrm{Na}^{+}$content of NG and SG plants, 4-5 times more than in INT and L (Fig. 6). While elevation of $\mathrm{Na}^{+}$content of $\mathrm{L}$ and INT 


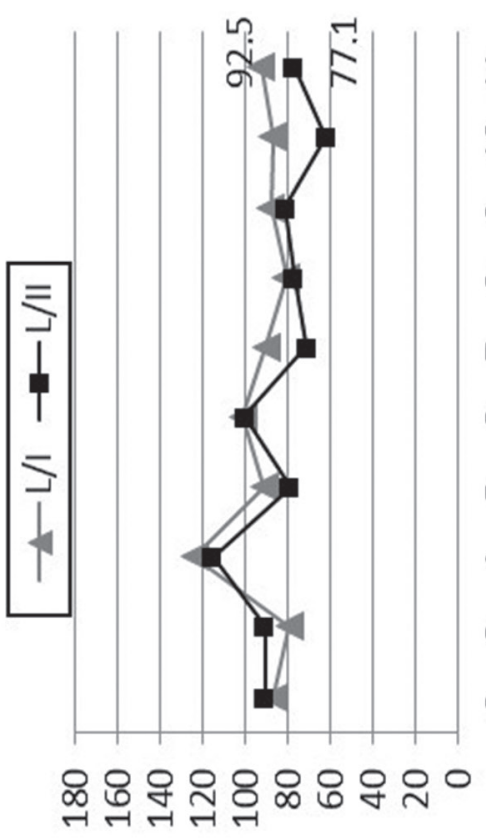

(\%) $\perp$

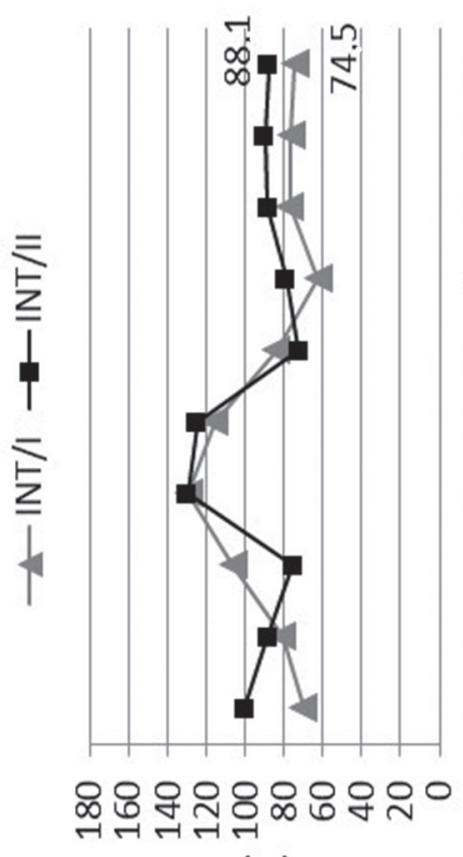

(\%) $\perp$

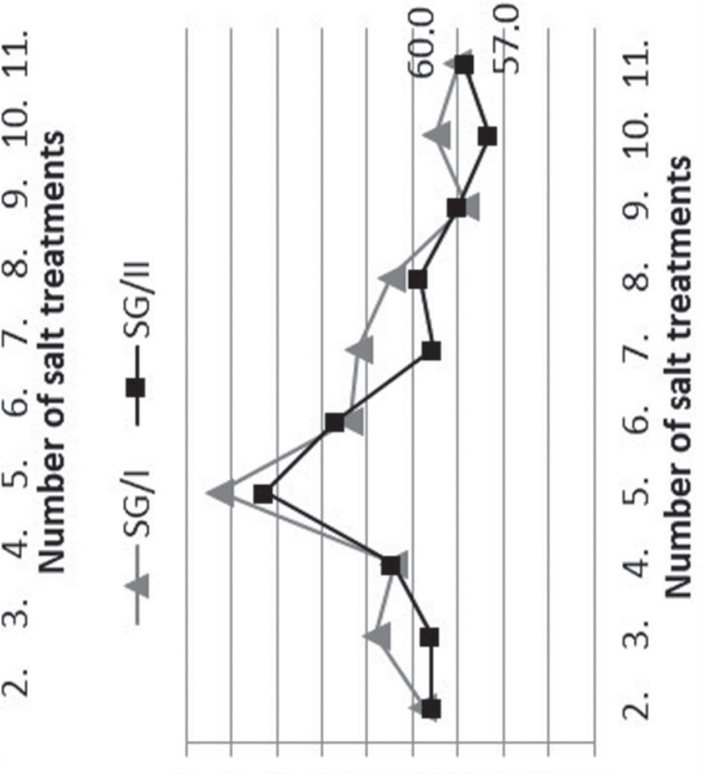

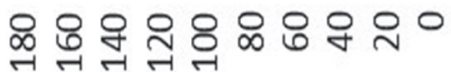

(\%) $\perp$

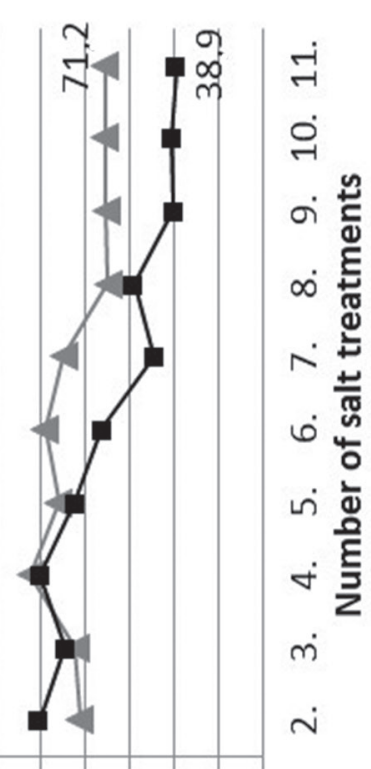

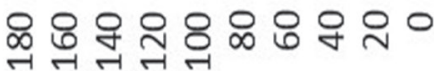

(\%) $\perp$

Acta Biologica Hungarica 68, 2017 

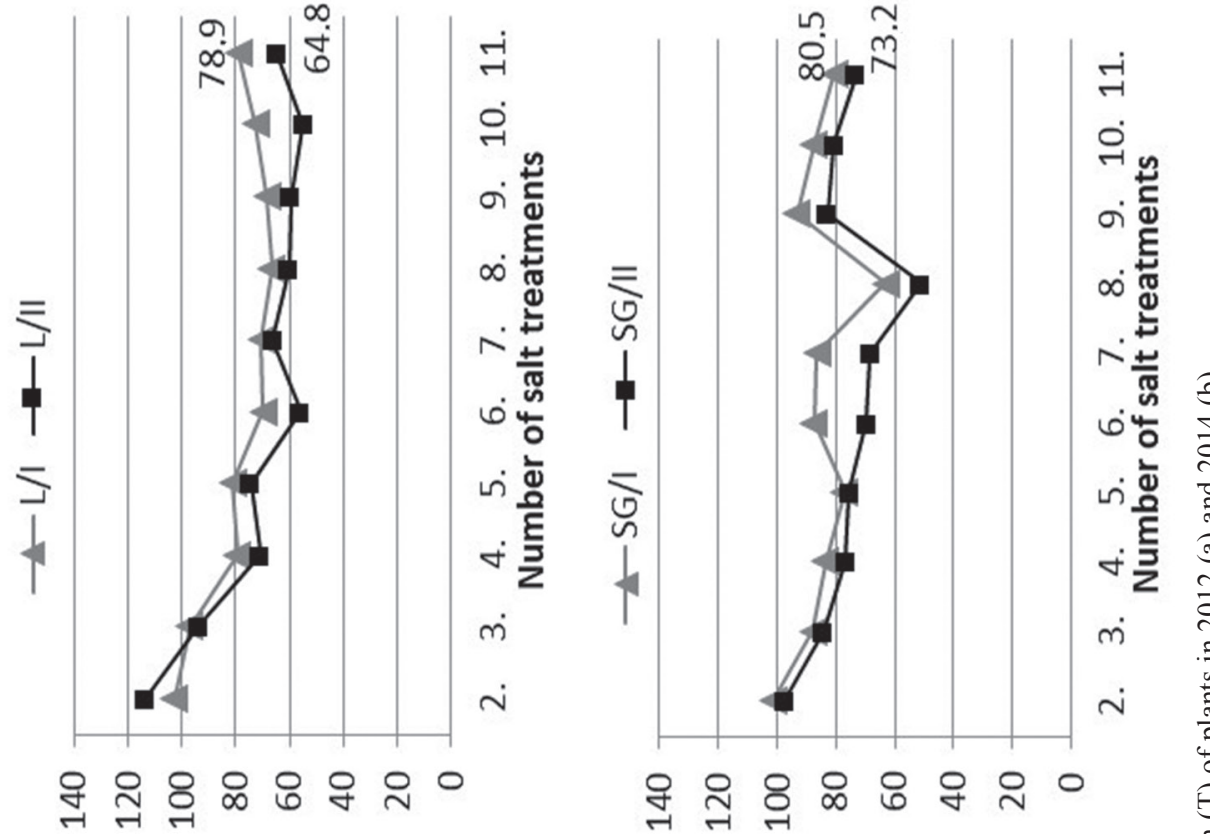

(\%) $\perp$

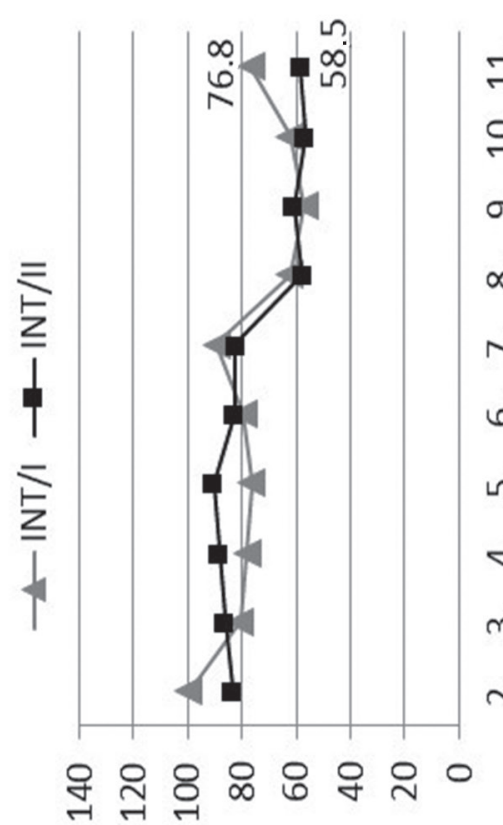

(\%) $\perp$

(\%) $\perp$

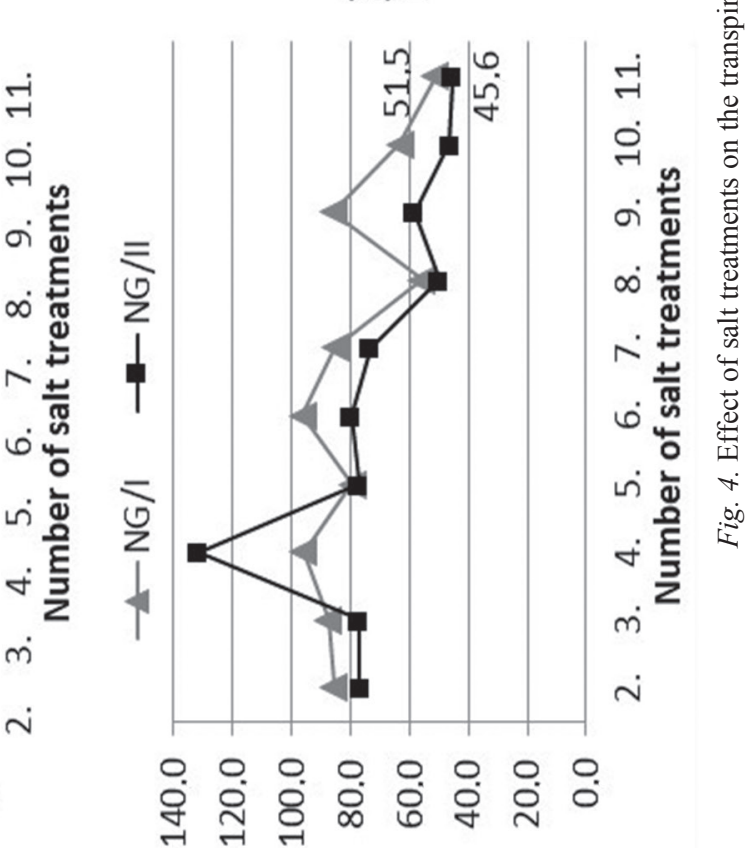

(\%) $\perp$ 
plants in the II salt treatment were still negligible compared to NG and SG plants. $\mathrm{Na}^{+}$ content of roots was also increased by salt treatments in all grafting combination, but those grafting combinations that took up less $\mathrm{Na}^{+}$into the leaves (L, INT) accumulated more in their roots opposite to NG and SG (except L in 2012).
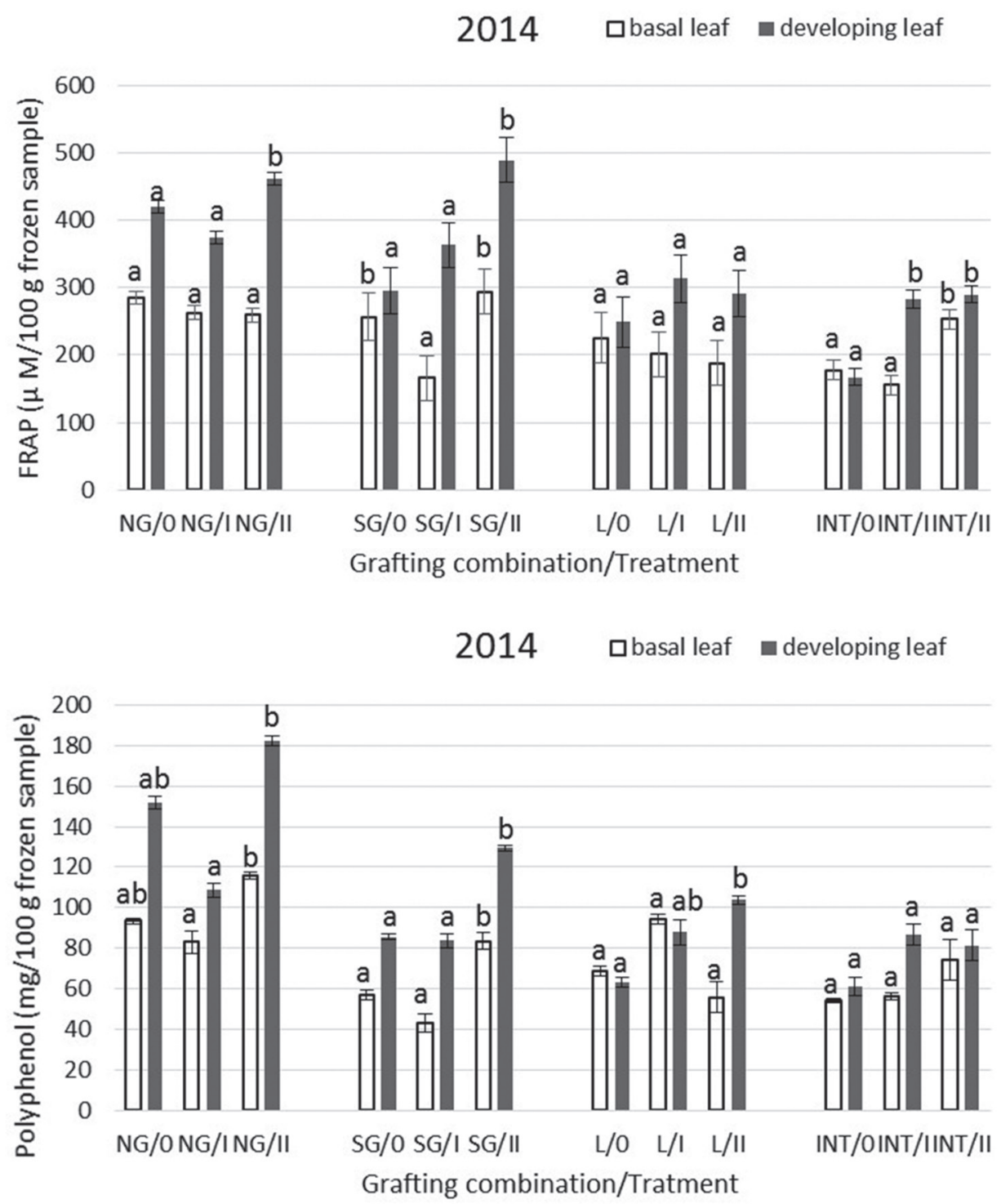

Fig. 5. Effect of salt stress on FRAP and polyphenol content. Note: Bars indicate s.e. and different letters indicate significant differences at $P<0.05$ 
$\square 2012 \square 2014$

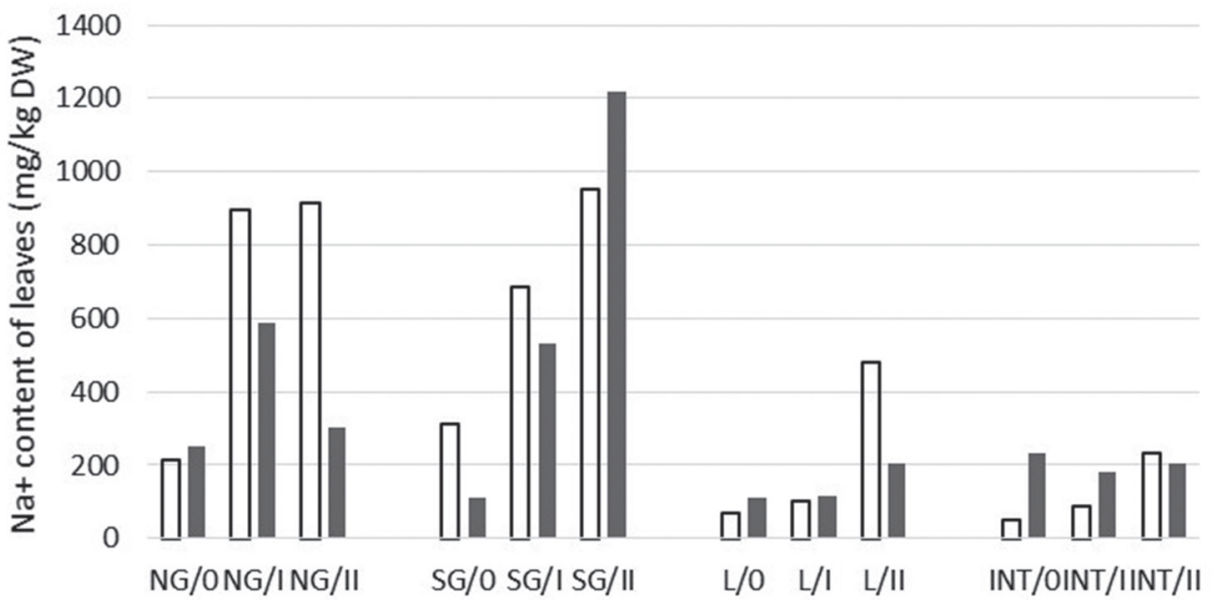

Grafting combination/Treatment

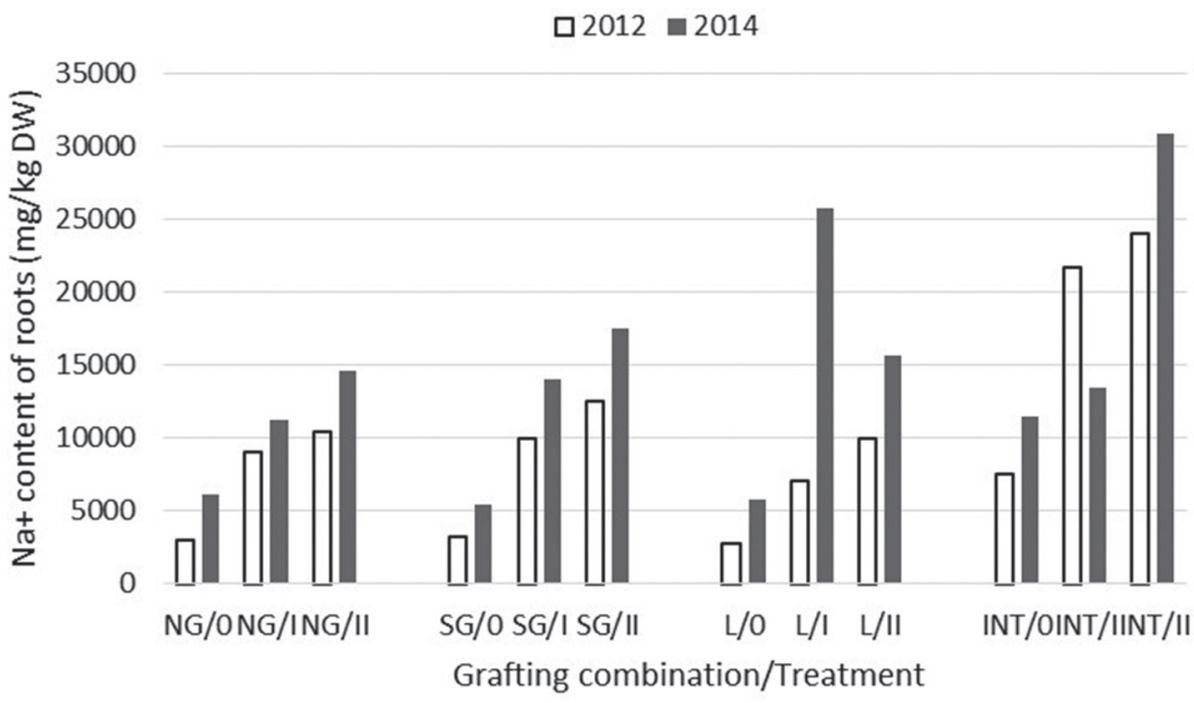

Fig. 6. The effect of $\mathrm{Na}^{+}$content of leaves and roots

\section{DISCUSSION}

Salinity stress results in decrease of the weight of shoot, root and leaf area. The main reason of leaf area reduction is due to low water uptake caused by osmotic changes that results in development of smaller leaf cells [17]. As reported by Goreta et al. [15], when watermelon ('Fantasy') was grafted onto 'Strongtosa' rootstock (Cucurbita 
maxima Duch. $\times$ Cucurbita moschata Duch.) the reductions in shoot weight and leaf area due to exposure to salinity were lower than in ungrafted plants. In our study LA and FW of INT plants not only did not decrease similarly to the other grafting combinations but even increased compared to control plants under salinity stress (both treatments in 2012 and treatment I in 2014). In contrast to our findings Colla et al. [8] observed the same decrease in leaf area by salinity stress in grafted watermelon onto interspecific and Lagenaria rootstock and non-grafted plants. In our study, significant difference in root DW caused by the salt treatments could only be detected in case of NG in 2014, where roots DW in II salt treatments dropped significantly compared to control. These findings are in line with the study of Colla et al. [8] where root weights of watermelon grafted onto Lagenaria and interspecific rootstock were multiple times higher than that of non-grafted ones, but did not decrease significantly by salinity. In our experiment, even a slight increase in roots DW was observed in the case of INT (2012, 2014) and L plants (2014) in II salt treatment compared to control, while NG and SG dropped. However the I treatment did not affect the root DW of SG plants but root DW of NG dropped gradually due to salinity.

A number of studies proved that grafting onto some rootstocks improves the photosynthesis performance of plants under salinity stress. Despite the fact that statistical analysis showed significant differences in all grafting combinations in the II treatment compared to control group in our experiment, photosynthetic activity in INT plants was still twice more intensive than in all other grafting combinations. Our findings stand in correlation to the study by Colla et al. [10] where salinity stress did not decrease photosynthetic activity of cucumbers grafted onto interspecific rootstocks as much as non-grafted ones. But in the study of Colla et al. [10] the interspecific rootstock did not increase the photosynthetic activity of the cucumber plants in the control treatment significantly as in our experiment in case of watermelon plants. In our study it was observed that the photosynthetic activity of the SG plants were significantly higher than the NG, sometimes it reached or even exceeded the L or INT plants. These results suggest that grafting per se can enhance the photosynthesis.

The salt treatments reduced the $T$ of all grafting combination. The level of decrease was most obvious in case of NG plants. The grafted plants, even the SG ones, maintained higher T compared to NG which suggests that grafting per se can enhance the salinity tolerance through the increased water uptake of grafted plants. INT plants showed more intensive $\mathrm{T}$ in the II treatment compared to I treatment for an extended period. This could be a physiological response to cope with osmotic stress and maintain water and nutrient uptake under severe salinity stress.

In plants, environmental stresses, such as salinity leads to increased secondary metabolites synthesis such as polyphenols and other antioxidant components to protect the cellular structure against oxidation $[6,12]$. In our study, the polyphenol content of leaves changes in relation to the FRAP. As FRAP increased as a result of salt treatments, polyphenol content of the leaves increased as well. Rezazadeh et al. [25] studied the salinity tolerance of artichokes, which is considered a salt tolerant plant species. They have found that lower salinity dose resulted in increased polyphenol content in leaves, but it decreased again when higher salinity dose was applied. The 
same tendency was found in our study in case L basal leaf and INT developing leaf. On the contrary, the lower salinity dose caused decrease in polyphenols compared to control, but the higher salinity dose resulted in significant increase in both leaf level of NG and SG plants.

In contrast to the exclusion of saline ions in the shoot, roots of rootstocks generally include more $\mathrm{Na}^{+}$and $\mathrm{Cl}^{-}$compared to self-rooted plants, as has been reported in the case of eggplants [34], watermelons [15, 38], and cucumbers [36, 37]. These findings are parallel to our study since the elevation of $\mathrm{Na}^{+}$content in the leaves of the L and INT plants were negligible comparing to SG and NG ones. On the contrary the $\mathrm{Na}^{+}$content of the roots were higher in the INT and L plants. In addition grafting per se may have a slight $\mathrm{Na}^{+}$retention effect itself because the $\mathrm{Na}^{+}$content in the leaves of SG plants were lower in the control and in I salinity treatment compared to $\mathrm{NG}$ plants. $\mathrm{Na}^{+}$retention of interspecific rootstock was confirmed by other studies as well $[21,29]$.

As a conclusion, in this study, grafting 'Esmeralda' watermelon variety onto Lagenaria and interspecific rootstocks significantly increased the performance of plants under salt stress. Both rootstocks have sodium retention, since the elevation of $\mathrm{Na}^{+}$content in the leaves of the L and INT plants were minor compared to SG and NG ones. This feature resulted in less toxic and osmotic effect, and enabled the plants to maintain their T and reduce the stress symptoms. Especially in INT, in which some measured parameters were not reduced (but increased even: FW, DW of shoot parts and roots, LA) by salinity treatment. Presumably, abiotic stress tolerance can be enhanced by grafting per se, as SG plants were more tolerant to salinity than NG ones. To confirm these assumptions more experiments are to be conducted.

\section{REFERENCES}

1. Ashraf, M. (1994) Organic substances responsible for salt tolerance in Eruca sativa. Biol. Plantarum $36,255-259$

2. Benzie, I. F., Strain, J. J. (1966) The Ferric Reducing Ability of Plasma (FRAP) as a measure of "antioxidant power": The FRAP essay. Anal. Biochem. 239, 70-76.

3. Borochov-Neori, H., Borochov, A. (1991) Response of melon plants to salt: 1. Growth, morphology and root membrane properties. J. Plant Physiol. 139, 100-105.

4. Bulder, H. A. M., Van Hasselt, P. R., Kuiper, P. J. C., Speek, E. J., Den Nijs, A. P. M. (1990) The effect of low root temperature on growth and lipid composition of low temperature tolerant rootstock genotypes for cucumber. J. Plant Physiol. 138, 661-666.

5. Cheeseuman, J. M. (1988) Mechanisms of salinity tolerance in plants. Plant Physiol 87, 547-550.

6. Chanwitheesuk, A., Teerawutgulrag, A., Rakariyatham, N. (2005) Screening of antioxidant activity and antioxidant compounds of some edible plants of Thailand. Food chemistry 92, 491-497.

7. Colla, G., Rouphael, Y., Cardarelli, M., Massa, D., Salerno, A., Rea, E. (2006a) Yield, fruit quality and mineral composition of grafted melon plants grown under saline conditions. J. Hortic Sci. Biotech. 81, 146-152.

8. Colla, G., Roupheal, Y., Cardarelli, M. (2006b) Effect of salinity on yield, fruit quality, leaf gas exchange, and mineral composition of grafted watermelon plants. Hortic Sci. 41, 622-627.

9. Colla, G., Rouphael, Y., Leopardi, C., Bie, Z. (2010) Role of grafting in vegetable crops grown under saline conditions. Sci. Hortic. Amsterdam 127, 147-155. 
10. Colla, G., Rouphael, Y., Reac, E., Cardarelli, M. (2012) Grafting cucumber plants enhance tolerance to sodium chloride and sulfate salinization. Sci. Hortic. Amsterdam 135, 177-185.

11. Davis, A. R., Perkins-Veazie, P., Sakata, Y., López-Galarza, S., Maroto, J. V., Lee, S. G., Huh, Y. C., Sun, Z., Miguel, A., King, S. R., Cohen, R., Lee, J. M. (2008) Cucurbit grafting. Crit. Rev. Plant Sci. 27, 50-74.

12. Dixon, R. A., Paiva, N. L. (1995) Stress-induced phenylpropanoid metabolism. The Plant Cell 7, 1085.

13. Edelstein, M., Ben-Hur, M., Cohen, R., Burger, Y., Ravina, I. (2005) Boron and salinity effects on grafted and non-grafted melon plants. Plant Soil 269, 273-284.

14. Estañ, M. T., Martinez-Rodriguez, M. M., Perez-Alfocea, F., Flowers, T. J., Bolarin, M. C. (2005) Grafting raises the salt tolerance of tomato through limiting the transport of sodium and chloride to the shoot. $J$ Exp Bot 56: 703-712.

15. Goreta, S., Bucevic-Popovic, V., Selak, G. V., Pavela-Vrancic, M., Perica, S. (2008) Vegetative growth, superoxide dismutase activity and ion concentration of salt stressed watermelon as influenced by rootstock. J. Agr. Sci. 146, 695-704.

16. Hasegawa, P. M., Bressan, R. A., Zhu, J. K., Bohnert, H. J. (2000) Plant cellular and molecular responses to high salinity. Annu. Rev. Plant Phys. 51, 463-499.

17. George, E., Horst, W., Neumann, E. (2012) Saline soil. In: Marschner, P. (ed.) Mineral nutrition of higher plants. Academic Press, New York, pp. 455-473.

18. Kaya, C., Kirnak, Higgs, H., Saltali, K. (2002) Supplementary calcium enhances plant growth and fruit yield in strawberry cultivars grown at high $(\mathrm{NaCl})$ salinity. Sci. Hortic. Amsterdam 93, 65-72.

19. Marschner, H. (1995) Saline soil. In: Mineral nutrition of higher plants. Academic Press, New York, pp. $657-680$.

20. Munns, R., Tester, M. (2008) Mechanisms of salinity tolerance. Annu. Rev. Plant Biol. 59, 651-681.

21. Orsini, F., Sanoubar, R., Oztekin, G. B., Kappel, N., Tepecik, M., Quacquarelli, C., Tuzel, Y., Bona, B., Gianquinto, G. (2013) Improved stomatal regulation and ion partitioning boosts salt tolerance in grafted melon. Funct. Plant Biol. 40, 628-636.

22. Otani, T., Seike, N. (2007) Rootstock control of fruit dieldrin concentration in grafted cucumber (Cucumis sativus). J. Pestic. Sci. 32, 235-242.

23. Proebsting, W. M., Hedden, P., Lewis, M. J., Croker, S. J., Proebsting, L. N. (1992) Gibberellin concentration and transport in genetic lines of pea effects of grafting. Plant Physiol 100, 1354-1360.

24. Pulgar, G.,Villora, G., Moreno, D. A., Romero, L. (2000) Improving the mineral nutrition in grafted watermelon plants: Nitrogen metabolism. Biol. Plantarum 43, 607-609.

25. Rezazadeh, A., Ghasemnezhad, A., Barani, M., Telmadarrehei, T. (2012) Effect of salinity on phenolic composition and antioxidant activity of artichoke (Cynara scolymus L.) leaves. Res. J. Med. Plant 6, 245-252.

26. Rivero, R. M., Ruiz, J. M., Romero, L. (2003a) Role of grafting in horticultural plants under stress conditions. J. Food Agric. Environ. 1, 70-74.

27. Rivero, R. M., Ruiz, J. M., Sanchez, E., Romero, L. (2003b) Does grafting provide tomato plants and advantages against $\mathrm{H}_{2} \mathrm{O}_{2}$ production under conditions of thermal shock? Plant Physiol. 117, 44-50.

28. Romera, F. J., Alcántara, E., De La Guardia, M. D. (1991) Characterization of the tolerance to iron chlorosis in different peach rootstocks grown in nutrient solution. Plant Soil 130, 121-125.

29. Romero, L., Belakbir, A., Ragala, L., Ruiz, M. (1997) Response of plant yield and leaf pigments to saline conditions: effectiveness of different rootstocks in melon plants (Cucumis melo L.). Soil Sci. Plant Nutr. 41, 855-862.

30. Rouphael, Y., Cardarelli, M., Rea, E., Colla, G. (2008) Grafting of cucumber as a means to minimize copper toxicity. Environ. Exp. Bot. 63, 49-58.

31. Ruiz, J. M., Belakbir, A., Lopez-Cantarero, I., Romero, L. (1997) Leaf macronutrient content and yield in grafted melon plants: a model to evaluate the influence of rootstocks genotype. Sci. HorticAmsterdam 71, 227-234. 
32. Serrano, R., Mulet, J. M., Rios, G., Marquez, J. A., de Larrinoa, I. F., Leube, M. P., Mendizabal, I., Pascual-Ahuir, A., Proft, M., Ros, R., Montesinos, C. (1999) A glimpse of the mechanisms of ion homeostasis during salt stress. J. Exp. Bot. 50, 1023-1036.

33. Singleton, V. L., Rossi, J. A. (1965) Colorimetry of total phenolics with phosphomolibdic-phosphotunstic acid reagents. Am. J. Enol. Viticult 161, 144-158.

34. Wei, G. Y., Zhu, Z., Liu, L., Yang, G., Zhang (2007) Growth and ion distribution in grafted eggplant seedling under $\mathrm{NaCl}$ stress. Acta Bot. Sin. 27, 1172-1178.

35. Yetisir, H., Uygur, V. (2010) Responses of grafted watermelon onto different gourd species to salinity stress. J. Plant Nutr. 33, 315-327.

36. Zhu, J., Bie, Z. L., Huang, Y., Han, X. Y. (2008) Effect of grafting on the growth and ion contents of cucumber seedlings under $\mathrm{NaCl}$ stress. Soil Sci. Plant Nutr. 54, 895-902.

37. Zhen, Z., Bie, Y., Huang, Z., Liu, Q. Li (2010) Effects of scion and rootstock genotypes on the antioxidant defense systems of grafted cucumber seedlings under $\mathrm{NaCl}$ stress. Soil Sci. Plant Nutr. 56, 263-271.

38. Zhu, S. N., Guo, S. R. (2009) Effects of Grafting on $\mathrm{K}^{+}, \mathrm{Na}^{+}$Contents and Distribution of Watermelon (Citrullus vulgaris Schrad.) Seedlings Under NaCl Stress. Acta Hortic Sin. 36, 814-820. 